\title{
El derecho a la defensa del alimentante en la legislación ecuatoriana
}

The right to defense of the feeder in Ecuadorian legislation

\author{
Gisela Karina Arreaga-Farias \\ ub.gisellarreaga@uniandes.edu.ec \\ Universidad Regional Autónoma de los Andes, Babahoyo \\ Ecuador \\ https://orcid.org/0000-0003-2007-9441 \\ Luna Romero Silvia-Mónica \\ db.silviamlr84@uniandes.edu.ec \\ Universidad Regional Autónoma de los Andes, Babahoyo \\ Ecuador \\ https://orcid.org/0000-0001-7948-7218
}

Recepción: 15 de septiembre 2021

Revisado: 25 octubre 2021

Aprobación: 15 de noviembre 2021

Publicación: 01 de diciembre 2021 


\section{Estimado Editor (a):}

Los sujetos procesales tendrán conocimientos de todas las actuaciones judiciales, a través de sus domicilios judiciales físicos o electrónicos y principalmente se les hará conocer sobre la sentencia emitida dentro del proceso. Los litigantes al no ser notificados con la sentencia pueden solicitar que se declare la nulidad del proceso, pues todo litigante tiene derecho a conocer del contenido del fallo o a recurrir el mismo, en caso de no estar de acuerdo con dicha resolución. Con respecto al procedimiento a seguirse en el juicio de alimentos hasta antes del año 2003, se ventilaba sujetándose a lo estipulado en el Código de Menores y por ende a un trámite denominado "especial"; juicios que tenían conocimiento los Tribunales de Menores (Institución adscrita al Ministerio de Bienestar Social), por cuanto dicho proceso los legisladores lo miraban como un problema social y no como un problema jurídico. La forma de citar a los demandados, en esa época, era a través de una boleta, que consistían en un cuarto de una hoja, en donde se llenaban ciertos datos, como los nombres de la actora y demandado, el número del Tribunal conocedor de la causa, el número y año del juicio.

Por el año 2003, al expedirse el Código de la Niñez y adolescencia, los Tribunales de Menores pasan a formar parte de la Función Judicial, tomando el nombre de los Juzgados de la Niñez y adolescencia. En Ecuador, los juicios de alimentos, desde el 2003, se sujetaban a un trámite denominado Contencioso General, que se ejecutaba en dos audiencias, consistentes en una audiencia de conciliación y en una audiencia de prueba. La citación al demandado/alimentante es esta clase de juicios se realizaba de acuerdo a las formas establecidas en el derogado Código de Procedimiento Civil, diligencia practicada por los citadores de la Función Judicial. En el 2009, el día 28 de julio se publica el Registro oficial 643, Registro que contiene la Ley Reformatoria al Título V, Libro II del Código de la Niñez y adolescencia; esto es, reformas al juicio de alimentos con respecto a su procedimiento, como las formas de citar al demandado, la ejecución del mismo en una sola audiencia.

En dicha Ley Reformatoria, se señala como una de las formas de citar al demandado, la boleta única de citación, documento que era entregado, con ayuda de la fuerza 
pública, al accionado poniendo en su conocimiento el contenido de la demanda. Esta forma de citar fue una innovación jurídica la cual tenía pro y su contra, pero que a la final daba resultados positivos como el de dar a conocer a la parte contraria el contenido de la demanda y el de determinar, mediante celeridad procesal, la pensión de alimentos de los derechohabientes.

En este sentido, según el Artículo 53 del Código Orgánico de Procesos (2015):

La citación es el acto por el cual se le hace conocer a la o al demandado el contenido de la demanda o de la petición de una diligencia preparatoria y de las providencias recaídas ene ellas. Se realizará en forma personal, mediante boletas o a través del medio de comunicación ordenado por la o el juzgador.

En la era de las computadoras, celulares, internet, en fin, el mundo está cambiando. Cada día los avances tecnológicos son más impresionantes e imprescindibles en nuestro día a día; a tal modo que la tecnología ha pasado de ser un lujo a ser una necesidad. El miércoles 11 de marzo 2020, se declaró oficialmente por la Organización Mundial de la Salud al COVID-19 como pandemia. En tal virtud, el Ecuador dispuso estado de excepción y declaró en cuarentena a todo el territorio nacional. Frente a conflictos legales las personas pueden ejercer su derecho de acción e interponer una demanda para que un juzgador resuelva el conflicto entre las partes, siempre velando por el derecho de estas. Con una amplia carga procesal los juicios están a la espera y los ciudadanos siguen sin resolver sus conflictos. Tal es la situación que en algunos casos ni siquiera sus procesos inician por falta de citación. Es por esto por lo que inmediatamente surge la pregunta: ¿Por qué no utilizar los medios electrónicos para realizar citaciones? Es pertinente denotar que el Código Orgánico General de Procesos prevé la posibilidad de realizar la citación a través del correo electrónico de la persona demandada; sin embargo, este mismo cuerpo legal aclara que esta no sustituye la citación oficial la cual debe ser realizada personalmente, por boletas o a través de los medios de comunicación. La respuesta es bastante sencilla, se estarían violentando derechos por parte de la administración de justicia al dejar en indefensión a cientos si no a miles de ciudadanos que puedan recibir una demanda sin poder defenderse adecuadamente. Asimismo, ¿Qué ocurre 
si los derechos de los ciudadanos están siendo violentados? Se interpondrán acciones de nulidad, acciones de protección en contra del estado y demás generando caos en el sistema judicial al ocasionar que la carga procesal sea aún más grande.

Es por esta razón que una citación por correo electrónico más allá de ser una herramienta para liberar la carga procesal podría generar herramienta para violación de derechos fundamentales, mismos que se encuentran reconocidos en nuestra Constitución y el Estado es el encargado de velar por estos mismos. A pesar de que una citación por correo electrónico parece innovador y prometedor, el Ecuador aún no está listo para adaptar esta medida. Mientras tanto será necesario explorar otras alternativas para mejorar la calidad y eficiencia de las citaciones dentro de los procesos judiciales. Quizás algún día, la red de telecomunicaciones en el Ecuador mejore y tan solo cuando cada familia de cada rincón del país tenga acceso a internet, se podría estar pensando en instaurar esta alternativa que, en principio, si tiene como fin agilitar el sistema de justicia para que las citaciones sean de manera inmediata, pero por el momento esta no es una medida viable. (Vera, 2021).

Al respecto, Cabanellas (2008):

La citación es la diligencia por la cual se hace saber a una persona el llamamiento hecho de orden del juez, para que comparezca en juicio a estar a derecho. Según esta definición la citación es un acto de aviso a una persona sobre diligencia en contra suya.

También se entiende en el sentido amplio, la citación es el llamamiento que hace la autoridad judicial a una persona para que comparezca ante dicha autoridad judicial con un objeto determinado que se le haga saber. En consecuencia, tenemos que la citación puede hacerse en las diversas formas por la ley: En persona (en cualquier lugar), 2) por boletas dejadas en la correspondiente habitación, 3) a los representantes de una compañía de comercio, en su respectivo establecimiento de comercio, y 4) a personas cuya individualidad o residencia sea imposible determinar se citará por tres publicaciones que se harán, cada una de ellas en fecha distinta, en un periódico de amplia circulación del lugar, de acuerdo al procedimiento que a continuación procederemos a detallar. Debiendo recalcar, que hasta que la citación no se realice en debida forma, no se produce la obligación de comparecer a una causa. 
A criterio de los investigadores, la forma más perfecta de efectuar la citación al demandado, es hacerlo en persona, ya que, de esta manera, no queda duda que se ha puesto en conocimiento del demandado respecto a un juicio o diligencia preparatoria iniciada en su contra, quedando a su libre albedrío decidir si comparece o no a juicio a defenderse. Por otro lado, la forma más común de citar a la parte demandada dentro de un proceso es mediante tres boletas que se entregarán en días distintos, la cual opera en aquellos casos en los que el accionado no ha podido ser citado en persona. El Artículo. 55 del COGEP, establece la posibilidad de este tipo de citación, siempre y cuando se trate del domicilio del demandado, en el caso de personas naturales se lo realizará en el domicilio y en lo que respecta a las personas jurídicas en el establecimiento donde funciona, siempre y cuando se mantenga activo. En este mismo orden de ideas, nos encontramos con los efectos de la citación, los cuales se encuentran enumerados en el COGEP (2015):

Artículo. 64.- Efectos. Son efectos de la citación: 1.- Requerir a la o el citado a comparecer ante la o el juzgador para deducir excepciones; 2.- Constituir a la o el demandado como poseedor de mala fe e impedir que haga suyos los frutos de la cosa que se le demanda, según lo dispuesto en la ley; $3 .-$ Constituir a la o el deudor en mora, según lo previsto en la ley; 4.Interrumpir la prescripción.

El principal efecto de la citación, conforme lo determina el numeral 1 del artículo citado, es lo que hemos venido citando, que es precisamente el llamamiento que hace el juez a que el demandado ejerza su derecho constitucional a la defensa.

Al respecto de este efecto de la citación, lo siguiente: En nuestro sistema, la citación de la demanda interrumpe el curso de la prescripción; no basta, entonces, la simple presentación de la demanda; es necesario que esta llegue al conocimiento del demandado, para que produzca el efecto legal de la interrupción; tanto, que para el evento de que la citación haya sido irregular (y se demuestre la irregularidad) igualmente no operaría la interrupción. (Morán, 2008)

La Constitución de la República del Ecuador (2008), así como también los diferentes tratados Internacionales relacionados con los derechos de las partes dentro de una contienda judicial, son unánimes al reconocer el derecho al debido proceso que posee 
toda persona dentro de un juicio, dentro del cual se encuentra precisamente el derecho a la defensa. En efecto, con la expedición de la Constitución de Montecristi en el año 2008, el Ecuador se ha proclamado como un Estado Constitucional de Derechos, y que no puede alegarse por parte de ninguna autoridad, falta de norma jurídica para justificar la inobservancia de derechos constitucionales, siendo inclusive responsable por error judicial y violación del derecho a la tutela judicial efectiva. En la especie, se evidencia la vulneración al derecho a la tutela judicial efectiva. Ahora, bien para que proceda la nulidad por falta de citación deberán concurrir dos presupuestos:

1) Que dicha omisión sea alegada por el demandado, al momento de comparecer a juicio $\mathrm{y}$;

2) Que le haya impedido formular excepciones o ejercer su derecho a la defensa, de acuerdo a lo previsto en el Art. 108.

En este sentido, una de las manifestaciones del derecho al debido proceso y derecho a la defensa dentro de un juicio se verifica con el correcto emplazamiento al accionado respecto de una demanda o acto preparatorio iniciado en su contra. Es decir, cuando se verifica la citación de acuerdo a las formas previstas en la Ley, para que sea considerada como válida. Por lo tanto, una correcta citación le da la oportunidad al demandado a que, dentro del término de Ley, pueda dar contestación a la demanda, presentando excepciones y aportando al juicio las pruebas de descargo, y alegaciones que considere convenientes a su favor. La citación es un acto procesal formal y solemne, que a su vez permite al demandado que ejerza su derecho a la contradicción, acorde a los principios procesales que rigen a la administración de justicia. La falta de citación, o que se la haya practicado incorrectamente ocasiona ineludiblemente la nulidad de lo actuado dentro del proceso, siempre y cuando influya en la decisión de la causa, ya que si ha existido indefensión se incurriría en nulidad.

\section{FINANCIAMIENTO}

No monetario. 
Iustitia Socialis. Revista Arbitrada de Ciencias Jurídicas

Año VI. Vol. VI. N 1 . Edición Especial. 2021

Hecho el depósito de Ley: FA2016000064 ISSN: $2542-3371$

FUNDACIÓN KOINONIA (F.K). Santa Ana de Coro, Venezuela

Gisela Karina Arreaga-Farias; Luna Romero Silvia-Mónica

\section{AGRADECIMIENTO}

A la Universidad Regional Autónoma de los Andes, Babahoyo, por motivar el desarrollo de la Investigación.

\section{REFERENCIAS CONSULTADAS}

Asamblea Nacional Constituyente de la República del Ecuador, (2008). Constitución de la República del Ecuador. [Constitution of the Republic of Ecuador]. Montecristi. Registro Oficial 449 de 20-oct-2008. Recuperado de https://n9.cl/sia

Cabanellas, G. (2008). Diccionario Jurídico Elemental. Edición Heliasta.

Código Orgánico General de Procesos. [General Organic Process Code]. Registro Oficial № 506, viernes 22 de mayo de 2015. Recuperado de https://n9.cl/z8haz

Congreso Nacional. (2003). Código de la niñez y adolescencia. [ Childhood and Adolescence Code]. Quito. Recuperado de: https://n9.cl/1w1fn

Constitución de la República. (2005) Código de Procedimiento Civil. [ Code of Civil Procedure]. Codificación 11 Registro Oficial Suplemento 58 de 12-jul-2005. Última modificación: 24-nov-2011.Recuperado de: https://n9.cl/p3y4a

Herrán Pinzón, O. A. (2013). El alcance de los principios de la administración de justicia frente a la descongestión judicial en Colombia. [ The scope of the principles of the administration of justice in the face of judicial decongestion in Colombia]. Prolegómenos, 16(32), 105-122.

Morán Sarmiento, R. E. (2008). Derecho Procesal civil práctico. Principios Fundamentales del Derecho Procesal. [Practical Civil Procedural Law. Fundamental Principles of Procedural Law]. Perú: Edilex S.A

Vera Zambrano, M. B. (2021). Reforma al Código Orgánico General de Procesos para validar la citación por correo electrónico a las personas jurídicas. [ Reform of the General Organic Code of Processes to validate the summons by email to legal entities]. (Bachelor's thesis). Universidad de Guayaquil, Facultad de Jurisprudencia Ciencias Sociales y Políticas, Ecuador. 